\title{
Assessment of left ventricular volume overload: comparison of 2-D echo and cardiac MRI
}

\author{
Julianne Matthews ${ }^{1,2^{*}}$, Nicholas C Boniface ${ }^{1,2}$, Brandon M Mikolich², John Lisko ${ }^{1,2}$, J Ronald Mikolich ${ }^{1,2}$ \\ From 17th Annual SCMR Scientific Sessions \\ New Orleans, LA, USA. 16-19 January 2014
}

\section{Background}

Left ventricular cavity dimensions and volumes are useful parameters to diagnose and monitor cardiac pathologies which lead to LV volume overload. 2-D echo/ Doppler is the most commonly used imaging modality to assess LV volume overload in patients with valvular regurgitant disease. However, 2-D echo suffers from inherent limitations related to adequacy of the intercostal echo window, anatomic positioning for cavity dimensions and volumes and incomplete visualization of the entire left ventricular cavity. This study was designed to compare assessment of LV cavity dimensions and volumes by $2-\mathrm{D}$ echo and cardiac magnetic resonance
(CMR) techniques in patients with LV volume overload due to valvular regurgitation

\section{Methods}

An institutional cardiac imaging database was queried to identify patients with at least moderate $(2+$ or greater) mitral regurgitation or aortic regurgitation who had 2-D and CMR studies within 6 months of each other. LV end-diastolic(LVIDd) and end-systolic(LVIDs) dimensions were tabulated, along with LV end-diastolic (LVEDV) and end-systolic(LVESV) volumes and severity of valvular regurgitation (1+ to 4+ scale) for both 2-D and CMR. 2-D regurgitation was estimated by Doppler
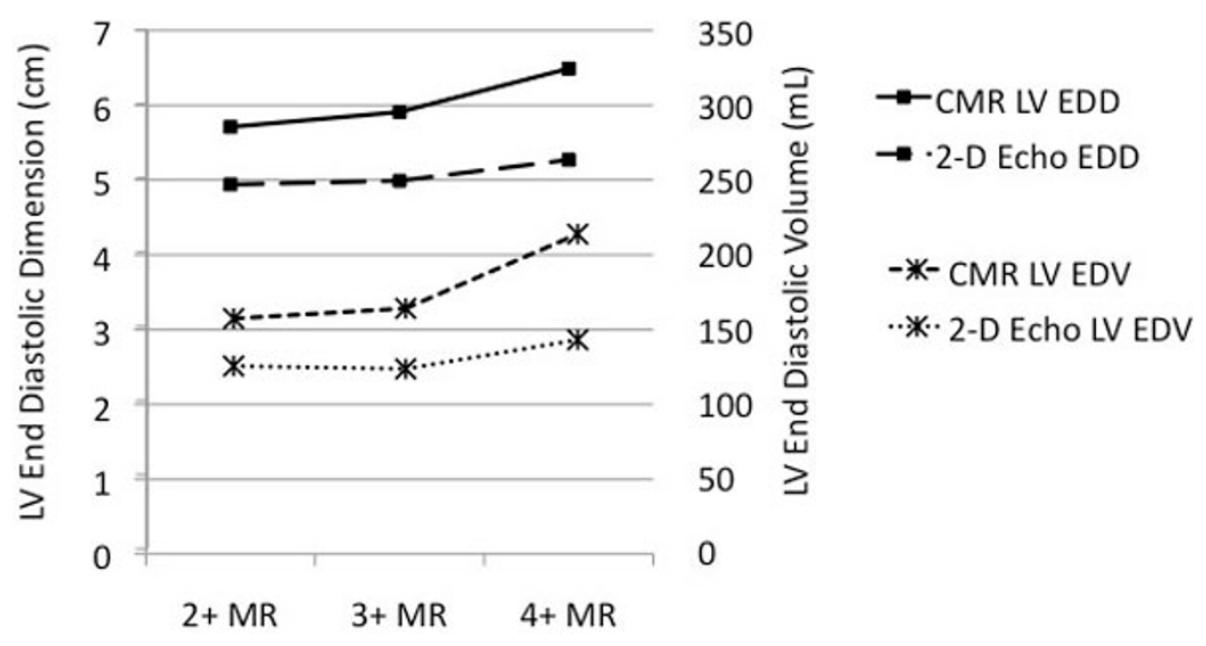

Severity of Mitral Regurgitation

Figure 1 Relationship of LV End-Diastolic Dimension and Volume to Severity of Mitral Regurgitation By 2-D Echo and CMR Methods.

${ }^{1}$ Northeast Ohio Medical University, Rootstown, Ohio, USA

Full list of author information is available at the end of the article

(c) 2014 Matthews et al.; licensee BioMed Central Ltd. This is an Open Access article distributed under the terms of the Creative Commons Attribution License (http://creativecommons.org/licenses/by/2.0), which permits unrestricted use, distribution, and 
analysis and CMR regurgitation was estimated by calculation of the regurgitant fraction using phase velocity mapping. The mean values for LVIDd, LVIDs, LVEDV and LVESV by 2-D and CMR were computed and statistically compared using a paired-sample t-test. Each parameter was also analyzed as a function of severity of regurgitation.

\section{Results}

Of 1,817 patients in the CMR database, 102 patients met study inclusion criteria, 52 with AR and 63 with MR. The mean LVIDd by CMR was $5.87 \mathrm{~cm}$ and $5.09 \mathrm{~cm}$ by 2-D $(\mathrm{p}<0.001)$. The mean LVIDs by CMR was $4.03 \mathrm{~cm}$ and $3.46 \mathrm{~cm}$ by $2-\mathrm{D}(\mathrm{p}<0.001)$. The mean LVEDV by CMR was $166.16 \mathrm{ml}$ and $129.48 \mathrm{ml}$ by $2-\mathrm{D}(\mathrm{p}<0.001)$. The mean LVESV by CMR was $77.71 \mathrm{~cm}$ and $56.06 \mathrm{ml}$ by 2-D $(\mathrm{p}<0.001)$. Parameter analysis as a function of severity of regurgitation is shown in the Figure 1.

\section{Conclusions}

In patients with LV volume overload due to valvular regurgitation, 2-D echo significantly underestimates LVIDd, LVIDs, LVEDV and LVESV, resulting in overestimation of global LV ejection fraction. In patients with mitral regurgitation, increases in LV end-diastolic dimension and LV end-diastolic volume on CMR are indicative of worsening regurgitation. A similar relationship to severity of mitral regurgitation could not be demonstrated for these parameters when assessed by 2-D echo techniques.

\section{Funding}

None.

Authors' details

${ }^{1}$ Northeast Ohio Medical University, Rootstown, Ohio, USA. ${ }^{2}$ Sharon Regional Health System, Sharon, Pennsylvania, USA.

Published: 16 January 2014

doi:10.1186/1532-429X-16-S1-P245

Cite this article as: Matthews et al: Assessment of left ventricular volume overload: comparison of 2-D echo and cardiac MRI. Journal of Cardiovascular Magnetic Resonance 2014 16(Suppl 1):P245.
Submit your next manuscript to BioMed Central and take full advantage of:

- Convenient online submission

- Thorough peer review

- No space constraints or color figure charges

- Immediate publication on acceptance

- Inclusion in PubMed, CAS, Scopus and Google Scholar

- Research which is freely available for redistribution

Submit your manuscript at www.biomedcentral.com/submit
C) Biomed Central 